\title{
NOVEL PHOTOISOMERIZATION OF SPIRODIENONES
}

\section{T.R. Kasturi, K.B. Ganesha Prasad, G. J. Raju and V. Ramamurthy Indian Institute of Science, Bangalore-560012, India.}

Abstract: Spironaphthalenones of the type (1) have been demonstrated to undergo isomerization to (2) upon UV irradiation.

2,4-Cyclohexadienones have been established to undergo 1,6-bond cleavage upon photolysis ${ }^{1,2}$. On the other hand, 6,6-spiroepoxy-2,4-cyclohexadienone is reported to result in aromatization via $\beta$ C-O bond cleavage upon excitation ${ }^{3}$. Here, we report a novel photoarrangement of spironaphthalenones [ (1) and (2)] involving $\beta$ C-O bond cleavage; rearrangement of such type is not common.<smiles>[R]C1=Cc2cc([R])cc([R3])c2C2(Oc3c([R])c([R])c([R])c([R])c3O2)C1=O</smiles><smiles>[R]C1=Cc2cc([R])cc([R3])c2C(=O)C12Oc1c([R])c([R])c([R])c([R])c1O2</smiles>

$\underline{2}$<smiles>[R]C1=C([R])C([R])=C([R])C2(Oc3c([R2])cc4cc([R])cc([R3])c4c3O2)C1=O</smiles>

$\underline{3}$

The spironaphthalenones $(\underline{1 b}-\underline{11})$ and $(\underline{2 b}-\underline{2 i})$ were prepared ${ }^{4}$ by the oxidation of the corresponding substituted $\beta$-naphthols with o-chloranil in benzene. Compounds (1a) and (2a) were prepared by the oxidation of 1-(2'-hydroxy-phenoxy)-2naphthol with o-chloranil in benzene.

Photolysis of benzene solution $(0,002-0,004 \mathrm{M})$ of (1) and (2) were carried out in pyrex tubes under deareated conditions using $450 \mathrm{~W}$ medium pressure mercury lamp. Results are presented in the table. Inspection of the table reveals that (la-lg) readily photoisomerize to $(\underline{2 a}-\underline{2 g})$ in near quantitative yield. On the other hand, spironaphthalenones (lh) and (li) photoisomerize to (2h) and (2i) respectively in reduced yields. Similar irradiation of (2a-2g) did not bring about any change whereas $(\underline{2 h})$ and $(\underline{2 i})$ rearranged to $(\underline{1 h})$ and $(\underline{1})$ respectively. The photosiomerization is believed to originate from the lowest excited singlet state, as triplet quenchers such as naphthalene ( $\left.\mathrm{E}_{\mathrm{T}}=61 \mathrm{Kcal} / \mathrm{m} \oplus \mathrm{le}\right)$ and cyclohexadiene $(52 \mathrm{Kcal} / \mathrm{mole})$ failed to quench the photorearrangement in the case of (Ib) and (lg). 
Table

Isomeric spirodienones

extent of isomerization (\%)
$(\underline{1}) \rightarrow(\underline{2})$
(2) $\rightarrow$ (1)

(1a) and (2a): $R_{1}=R_{2}=R_{3}=R=H$

100

0

(1b) and (2b): $R_{1}=R_{2}=R_{3}=H ; R=C l$

100

0

(1c) and ( $\underline{2 \mathrm{C}}$ ): $\mathrm{R}_{1}=\mathrm{R}_{2}=\mathrm{H} ; \mathrm{R}_{3}=\mathrm{Me} ; \mathrm{R}=\mathrm{Cl}$

100

0

(1d) and (2d): $R_{1}=R_{2}=H ; R_{3}=p r^{1} ; R=C l$

90

0

(1e) and (2et: $R_{1}=R_{2}=$ but ${ }^{t} ; R_{3}=H, R=C l$

100

0

(1f) and (2f) : $\mathrm{R}_{1}=\mathrm{R}_{3}=\mathrm{H} ; \mathrm{R}_{2}=\mathrm{bu}^{\mathrm{t}} ; \mathrm{R}=\mathrm{Cl}$

$90 \quad 0$

$(\underline{\mathrm{lg}})$ and $(\underline{2 \mathrm{~g}}): \mathrm{R}_{1}=\mathrm{CN} ; \mathrm{R}_{2}=\mathrm{R}_{3}=\mathrm{H} ; \mathrm{R}=\mathrm{Cl}$.

95

0

(1h) and (2h): $R_{1}=$ OMe: $R_{2}=R_{3}=H ; R=C l$

25

75

(11) and (21): $\mathrm{R}_{1}=\mathrm{Br} ; \mathrm{R}_{2}=\mathrm{R}_{3}=\mathrm{H} ; \mathrm{R}=\mathrm{Cl}$

75

25

The photorearrangement could be visualized as occurring through the intermediacy of spirocyclohexadienone of the type ( 3 ) formed by initial $\beta$ C-O cleavage. Further work, to have a deeper insight into its mechanism is under progress.

Acknowledgement: We wish to thank Mr。V. Ramesh for helpful discussions. One of us (K.B.G.) wish to thank the Department of Atomic Energy for financial assistance.

\section{References:}

1) G. Quinkert, Angew。 Chem. Internat, edn。, 11 1072 (1972): H. Hart, D. A. Dickinson and $W_{0} Y_{0}$ Li, Tetrahedron Lett., 2253 (1975); G. Quinkert, Pure. Appl. Chem., 35285 (1973); G。 Quinkert, F。 Cech, E。 Kleiner and D. Rehm, Angew。 Chem。 internat. edn。, 18557 (1979)。

2) T. Sala and M.V. Sargent, J. Chem, Soce. Perk。 Trans. I, 870 (1981).

3) H.D. Becker, T. Bremholt and E. Adler. Tetrahodron Lett. 4205 (1972).

4) T. R. Kasturi, T. Arunachalam and G。 Subramanyam, J. Chem。 Soc. (c) 1257 (1970): T.R. Kasturi and R。 Sivaramakrishnan, Indian. J. Chem。 $16 \mathrm{~B} 668$ (1978).

5) T. R. Kasturi, K. B. Ganesha Prasad and B. Rajasekhar, Indian J. Chem.• 21B 813 (1981)。

(Received in UK 29 February 1984) 